\title{
Accuracy of ultrasound-guided core-needle biopsy confronted with pathological findings and comparison of its costs with vacuum-assisted biopsy's costs.
}

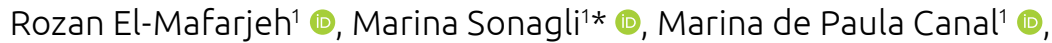

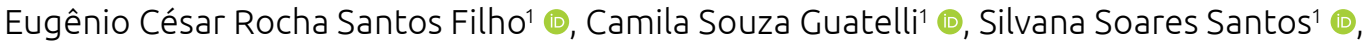

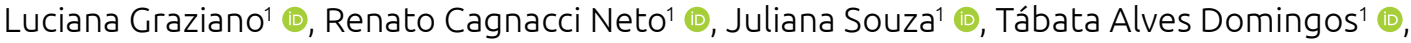

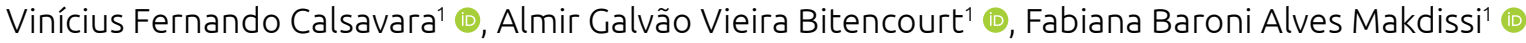

\section{ABSTRACT}

Introduction: Breast cancer screening has enhanced early-stage diagnosis by detection of impalpable tumors which require histopathological evaluation. Main percutaneous biopsy types are core-needle biopsy (CNB) and vacuum-assisted biopsy (VAB). CNB is less invasive and related to less bleeding and pain. VAB allows larger tissue samples and permits metal clip placement in biopsy bed for posterior localization in case of surgery. Access to VAB is restricted in Brazil due to its high costs. Objectives: To evaluate the agreement between pathological results of ultrasound (US) guided CNB with metal clip placement and surgery and settle false negative rates (FNR), sensibility, specificity, and accuracy of this method, for breast lesions $<20 \mathrm{~mm}$. Methods: 388 US-guided CNB were retrospectively reviewed. Results: Surgical excision was performed in 317 patients. Overall FNR was 9.8\%, (5.2\% for lesions 10-20 mm), sensibility $90.2 \%$ (94.8\% for lesions 10-20 mm), specificity $94.9 \%$ ( $94.1 \%$ for lesions $10-20 \mathrm{~mm}$ ), and accuracy $91.1 \%$ ( $94.7 \%$ for lesions $10-20 \mathrm{~mm}$ ). Cost of VAB varies from 2.2 to 12.5 times US-guided CNB. With metal clip placement, VAB costs 1.95 to 5.2 times US-guided CNB. Conclusions: For lesions that can be identified in US, CNB with metal clip placement has high sensitivity, specificity, and accuracy, as well as low FNR.

KEYWORDS: core needle biopsy; breast tumor; image-guided biopsy; clip; breast carcinoma.

\section{INTRODUCTION}

Breast cancer (BC) incidence is rising in low-income and middleincome countries due to improvement in life expectancy, urbanization, and adoption of Western lifestyles ${ }^{1,2}$. In the context of breast screening programs, detection of small and non-palpable lesions is increasing ${ }^{3}$. Suspicious lesions require histopathological evaluation and percutaneous breast biopsy has become an alternative to open surgical biopsy in these cases ${ }^{3}$. The main types of percutaneous breast biopsy are core-needle biopsy $(\mathrm{CNB})^{3}$ and vacuum assisted biopsy $(\mathrm{VAB})^{4}$. CNB is less invasive and related to less bleeding and less pain, since it uses a thinner needle. VAB allows larger tissue samples through a single skin puncture without need to repeatedly relocate the needle when a tethered device is used ${ }^{3,4}$.

Studies have reported false-negative rates (FNR) of 1.1\%-3.3\% for $\mathrm{CNB}$ and $0.6 \%-3.5 \%$ for $\mathrm{VAB}^{4}$. In small lesions, percutaneous biopsies, especially VAB, can completely remove the lesion. Inserting of a metal clip into the biopsy bed is necessary for subsequent identification of the area to be resected in the event of surgery ${ }^{5}$. In clinical practice, placement of a metal clip is routinely done in VAB but not in CNB. In A.C. Camargo Cancer Center, since 2012, it has been our preference to place a metal clip in selected CNB cases, especially when there is a higher suspicion for malignancies ${ }^{6}$.

The health system organization in Brazil is based on two financial sources: the public health system and the private system, composed by health insurances or self-funding ${ }^{1}$. Approximately $75 \%$ of the population has access only to public health care ${ }^{7}$. The Brazilian public health system and some health insurers do not provide access to VAB due to costs. It is estimated that costs associated to VAB are ten times higher than standard $\mathrm{CNB}^{8}$.

${ }^{1}$ A.C. Camargo Cancer Center - São Paulo (SP), Brazil.

*Corresponding author: marina.sonagli@accamargo.org.br

Conflict of interests: nothing to declare.

Received on: 01/16/2020. Accepted on: 05/06/2020. 
The objective of this study is to evaluate pathological diagnosis of ultrasound (US) guided CNB and surgery, setting falsenegative rate, sensibility, specificity, accuracy, positive predictive value (PPV), negative predictive value (NPV), upgrading rate and agreement rate of US guided CNB for breast lesions smaller than $2 \mathrm{~cm}$. Also, this study aims to estimate costs between VAB and CNB with and without metal clip placement.

\section{METHODS}

This study was approved by the Ethics Committee of A.C.Camargo Cancer Center, reference number 2,522/18. Due to the retrospective nature of the study, formal consent is not required. A retrospective cohort study encompassing women submitted to US-guided CNB breast lesions smaller than $2 \mathrm{~cm}$ with metal clip placement, between October 2016 and December 2017, extracted from the A.C.Camargo Cancer Center medical records.

US-guided CNB was performed using free-hand technique, guided by a 5-12 MHz linear-array transducer. After local anesthesia, a 14-gauge semi-automated needle was inserted by the radiologist through a small skin incision and advanced towards the target lesion using US guidance. Once needle location is confirmed, four or five core samples were obtained, as decided by each radiologist. Samples were immediately fixed in small formalin containers. A metallic clip was placed on the biopsy site at the end of the sampling and a post-biopsy mammogram was performed to confirm proper lesion targeting. Biopsies were performed by a team of radiologists, including medical residents supervised by radiologists with 5 to 25 years of experience in percutaneous biopsy.

Imaging findings of biopsied breast lesion and pathologic results of CNB were described in absolute and relative frequencies. Baseline patient characteristics were expressed as absolute and relative frequencies for qualitative variables and as the median, minimum, and maximum values for quantitative variables. Costs of $\mathrm{CNB}$ with and without metal clip placement and VAB were estimated through the average costs between the health insurances attended at A.C. Camargo. Data regarding costs were provided by financial department. Costs were compared by financial source and expressed as relative frequency.

False negative rates were calculated for lesions smaller than $10 \mathrm{~mm}$ or $10-20 \mathrm{~mm}$. Upgrading rate was calculated when CNB resulted atypical or benign, but surgery diagnosed a malignant lesion. All statistical analyses were carried out with the Statistical Package for Social Science (SPSS) version 25 (IBM Corp., Armonk, NY, USA).

\section{RESULTS}

Percutaneous US-guided CNB with metal clip placement was performed in 388 female patients between October 2016 and December
2017. Patients' mean age was 53.3 years-old (range, 20-94 years; mean \pm standard deviation [SD], $53.3 \pm 13.4$ ). Ultrasound findings of biopsied lesions were masses (91.2\%) and nonmass findings (8.8\%) (Table 1). Mean size of biopsied lesions was $12.2 \mathrm{~mm}$ (range, 3-20 mm; mean \pm SD. $12.2 \pm 4.5$ ). Pathologic results of US-guided CNB diagnosed invasive ductal carcinoma (49.7\%), invasive lobular carcinoma (2.6\%), ductal carcinoma in situ (4.6\%), lesions of high-risk (3.4\%), and benign findings (29.4\%) (Table 2).

Some lesions were surgically excised, and the choice of surgery was made at the discretion or request of the physician or patient. Of the 388 patients included in this study, 317 patients (81.7\%) underwent surgery after biopsy: 221 patients $(69.7 \%)$ underwent conservative surgery and 96 patients (30.6\%) underwent mastectomy. For adequate intraoperative localization, lesion or metal clip was pre-operatively marked by US-guided injection of technetium ${ }^{99}$ (radio-guided occult lesion localization - ROLL) in $225(86.9 \%)$ patients.

Table 3 summarizes histological findings of US-guided CNB and surgery for lesions smaller than $10 \mathrm{~mm}$ and between 10 to $20 \mathrm{~mm}$, and for masses/lumps and nonmasses findings. Two cases of false-positive were identified. One case refers to a patient submitted to neoadjuvant chemotherapy who presented a complete

Table 1. Characteristics of US-guided core-needle biopsy breast lesions with metal clip placement.

\begin{tabular}{l|c} 
Image findings of biopsied lesions & $\mathbf{n}(\%)$ \\
\hline Lumps/Masses & $354(91.2)$ \\
\hline Nonmass Findings & $34(8.8)$ \\
\hline
\end{tabular}

US: ultrasound.

Table 2. Pathologic findings of breast ultrasound-guided core-needle biopsy with metal clip placement.

\begin{tabular}{l|c}
\hline Pathologic Findings of biopsied lesions & $\mathbf{n}(\%)$ \\
\hline Breast Cancer & $221(56.9)$ \\
\hline Invasive Ductal Carcinoma & $193(49.7)$ \\
\hline Invasive Lobular Carcinoma & $2.6)$ \\
\hline Ductal Carcinoma in situ & $18(4.6)$ \\
\hline High-risk & $13(3.4)$ \\
\hline Atypical Ductal Hyperplasia & $7(1.8)$ \\
\hline Atypical Lobular Hyperplasia & $(0.8)$ \\
\hline Lobular Carcinoma in situ & $3(0.8)$ \\
\hline Benign & $114(29.4)$ \\
\hline Fibroadenoma & $47(12.1)$ \\
\hline Stromal Fibrosis of breast tissue & $39(10.1)$ \\
\hline Pseudoangiomatous Stromal Hyperplasia (PASH) & $3(0.8)$ \\
\hline Papillary Lesion & $25(6.4)$ \\
\hline Others & $40(10.3)$ \\
\hline Total & $388(100)$ \\
\hline
\end{tabular}


pathological response. Second case regards to the absence of residual tumor in surgery due to its removal on biopsy. According to the pathological report of this case, tumor comprised $90 \%$ of the biopsy material, which measured $1.7 \mathrm{~cm}$.

Overall FNR for US-guided CNB with metal clip placement was $9.8 \%$, higher for lesions smaller than $10 \mathrm{~mm}(16.2 \%)$ and lower for lesion ranging 10-20 mm (5.2\%). When compared by radiologic findings, FNR was $0.9 \%$ for masses/lumps and $6.7 \%$ for nonmasses lesions (Table 4).

Overall sensibility overall was $90.2 \%$ (83.8\% for lesions $\leq 10 \mathrm{~mm}$; $94.8 \%$ for lesions $10-20 \mathrm{~mm}$ ) and overall specificity was $94.9 \%$ ( $96 \%$ for lesions $\leq 10 \mathrm{~mm}$; $94.1 \%$ for lesions $10-20 \mathrm{~mm}$ ). US-guided CNB sensibility for masses/lumps was 99.1\%, slightly higher than for nonmasses (93.3\%) (Table 4).

Overall PPV and NPV were 98.7 and 69.1\%. For lesion $\leq 10 \mathrm{~mm}$, values were $98.8 \%$ and $60 \%$ and for lesions $10-20 \mathrm{~mm}, 98.6 \%$ and
$80 \%$, respectively. PPV and NPV for masses/lumps were $90.8 \%$ and 95.9\%. Overall accuracy rate was $91.1 \%$ (86.3\% for lesions $\leq 10 \mathrm{~mm}$ and $94.7 \%$ for lesions $10-20 \mathrm{~mm}$ ). Accuracy for masses/lumps was $91.6 \%$. Overall upgrading rate between pathological finding of CNB and surgery was $7.1 \%$, being higher for lesions $\leq 10 \mathrm{~mm}$ (12.1\%) than for lesions 10-20 mm (3.7\%) (Table 4).

Comparison between costs of US-guided CNB with and without metal clip placement and VAB according to financial source (private versus healthcare insurance) is displayed in Table 5. Cost of VAB was 2.2 times higher than US-guided CNB when payment source is private (i.e., paid by the patient) and 12.5 times higher when payment is provided by healthcare insurers. Introduction of a metal clip at the time of CNB entails a higher cost to the procedure, but, even so, VAB is more expensive and costs 1.95 times more than US-guided CNB when payment source is private and 5.2 times more when payment is by insurers (Table 5).

Table 3. Pathologic results of the US-guided core-needle biopsy biopsies versus pathological results of surgical specimen.

\begin{tabular}{|c|c|c|c|c|c|c|}
\hline \multirow{2}{*}{\multicolumn{3}{|c|}{ Size (mm) }} & \multicolumn{3}{|c|}{ Surgery } & \multirow{2}{*}{ Total } \\
\hline & & & Benign & Malign & Atypical & \\
\hline \multirow{4}{*}{$<=10$} & \multirow{3}{*}{ Biopsy } & Benign & 24 & 11 & 5 & 40 \\
\hline & & Malign & 0 & 72 & 2 & 74 \\
\hline & & Atypical & 1 & 4 & 5 & 10 \\
\hline & Total & & 25 & 87 & 12 & 124 \\
\hline \multirow{4}{*}{$>10$} & \multirow{3}{*}{ Biopsy } & Benign & 32 & 5 & 3 & 40 \\
\hline & & Malign & 2 & 139 & 0 & 141 \\
\hline & & Atypical & 0 & 2 & 5 & 7 \\
\hline & Total & & 34 & 146 & 8 & 188 \\
\hline \multirow{4}{*}{ Total } & \multirow{3}{*}{ Biopsy } & Benign & 56 & 16 & 8 & 80 \\
\hline & & Malign & 2 & 211 & 2 & 215 \\
\hline & & Atypical & 1 & 6 & 10 & 17 \\
\hline & Total & & 59 & 233 & 20 & 312 \\
\hline \multirow{2}{*}{\multicolumn{3}{|c|}{ Radiologic Findings }} & \multicolumn{3}{|c|}{ Surgery } & \multirow{2}{*}{ Total } \\
\hline & & & Benign & Malign & Atypical & \\
\hline \multirow{4}{*}{ Nonmasses } & \multirow{3}{*}{ Biopsy } & Benign & 9 & 2 & 1 & 12 \\
\hline & & Malign & 1 & 12 & 0 & 13 \\
\hline & & Atypical & 0 & 0 & 2 & 2 \\
\hline & Total & & 10 & 14 & 3 & 27 \\
\hline \multirow{4}{*}{ Masses/Lumps } & \multirow{3}{*}{ Biopsy } & Benign & 47 & 15 & 7 & 69 \\
\hline & & Malign & 1 & 200 & 2 & 203 \\
\hline & & Atypical & 1 & 6 & 8 & 15 \\
\hline & Total & & 49 & 221 & 17 & 287 \\
\hline \multirow{4}{*}{ Total } & \multirow{3}{*}{ Biopsy } & Benign & 56 & 17 & 8 & 81 \\
\hline & & Malign & 2 & 212 & 2 & 216 \\
\hline & & Atypical & 1 & 6 & 10 & 17 \\
\hline & Total & & 59 & 235 & 20 & 314 \\
\hline
\end{tabular}

US: ultrasound. 


\section{DISCUSSION}

Advancements in imaging technology and increased access to screening programs allow for the detection of non-palpable breast lesions, which require a pathological examination if suspicious for malignancy. Two indicators of the reliability of a pathological diagnosis of a percutaneous biopsy are the repeat biopsy rate (RBR) and FNR ${ }^{4}$. RBR is the rate at which a repeat needle biopsy or a surgical biopsy is performed after a benign result ${ }^{4}$. RBR for VAB and CNB are reported to range from $5.7 \%-14 \%$ and $10.9 \%-$ $17 \%$, respectively, and vary with needle size $e^{4,9}$.

FNR of US-guided CNB may vary according to breast lesion size and CNB needle size. A Chinese study evaluated 955 breast lesions biopsied by US-guided CNB and concluded that US-guided $\mathrm{CNB}$ is better for breast lesions bigger than $10 \mathrm{~mm}$, and, for lesions $\leq 10 \mathrm{~mm}$, a larger core needle caliber or VAB may be necessary ${ }^{10}$. In this same study, FNR for breast lesions $\leq 10 \mathrm{~mm}$ was $4.3 \%$ and $0.7 \%$ when $>10 \mathrm{~mm}^{10}$. As in the Chinese study, our data demonstrated that US-guided CNB is better for lesions higher than $10 \mathrm{~mm}$. However, higher FNR reported in this study might be due to our smaller sample size, as well as we considered lesions between 10 and $20 \mathrm{~mm}$.

Overall FNR for US-guided CNB are reported to range from $0 \%$ to $11.8 \%{ }^{11}$. Overall FNR for Us-guided VAB are reported to be $1 \%-5.2 \%{ }^{4,12}$. Overall FNR of this study was $9.8 \%$, in accordance to FNR reported in literature for US-guided CNB.

Sensibility, specificity, and accuracy of CNB has been described for palpable $(93.6 \%, 88.7 \%$, and $90.8 \%$ respectively) and not palpable lesions $(94.5 \%, 87.8 \% \text {, and } 90.5 \%)^{13}$. A Brazilian study evaluated 88 patients submitted to VAB and posterior excisional biopsy, where US-guided VAB sensibility was of $84.2 \%$, specificity of $100 \%$, PPV of $100 \%$, and NPV of $98 \%{ }^{14}$. Comparing the results of our study, US-guided CNB with metal clip placement has a higher sensibility than US-guided VAB and a higher specificity and accuracy than US-guided CNB. Also, our data showed a great PPV, slightly lower than reported to US-guided VAB. However, NPV of our study is much lower than reported from US-guided VAB, especially for lesions $\leq 10 \mathrm{~mm}$. Hence, we suggest that a benign result of a US-guided CNB biopsy should be followed up by imaging exams in 6 months or surgically excised, in cases of radiologic-clinical disagreement.

Lesions at high-risk comprise 3\%-9\% of CNB results and include papillary lesions, radial scar, atypical ductal hyperplasia (ADH), atypical lobular hyperplasia (ALH), lobular carcinoma in situ (LCIS), and fibroepithelial tumors9. In our study, 3.4\% of histological CNB findings are high-risk lesions, according to what is reported in the literature. Upgrading rate includes benign or atypical lesions in CNB that were diagnosed as malignant lesions after surgery. Upgrading rates for ADH in ductal carcinoma in situ (DCIS) or invasive carcinoma (ICD) are reported to be $12 \%-54 \%$, and factors associated to upgrading rate are ipsilateral breast symptoms, use of $14 \mathrm{G} \mathrm{CNB}$ in comparison of $11 \mathrm{G} \mathrm{CNB}$, severe $\mathrm{ADH}$ and co-diagnosis of papilloma ${ }^{15}$. Upgrading rates of $\mathrm{VAB}$ is reported to range from $10 \%-20 \% \%^{9,12}$. The overall upgrading rate found in this study (7.1\%) is smaller than the reported in the literature, even lower when considered for lesions $10-20 \mathrm{~mm}$ (3.7\%).

Main limitation of VAB is related to its costs. Alonso-Bartolomé et al. ${ }^{8}$ analyzed the financial outlays of VAB and concluded that VAB systems are ten times more expensive than standard $\mathrm{CNB}$, but $82 \%$ lower than surgical biopsies. In Japan, VAB costs around three times more than $\mathrm{CNB}^{4}$. In US, Grady et al. ${ }^{16}$ showed that there is no difference between costs of US-guided CNB and non-tethered VAB devices, but when compared only tethered $\mathrm{VAB}$ devices and CNB, VAB is better cost-effective. To calculate costs of VAB and CNB, Grady et al. ${ }^{16}$ included repeated biopsies

Table 4. False negative rate (FNR), sensibility, specificity, positive predictive value (PPV), negative predictive value (NPV), accuracy, and upgrading rate of US-guided core-needle biopsy.

\begin{tabular}{l|c|c|c|c|c|c|c}
\hline Size $(\mathrm{mm})$ & FNR $(\%)$ & Sensibility (\%) & Specificity (\%) & PPV (\%) & NPV (\%) & Accuracy (\%) & Upgrading (\%) \\
\hline$\leq 10$ & 16.2 & 83.8 & 96 & 98.8 & 60 & 86.3 & 12.1 \\
\hline $10-20$ & 5.2 & 94.8 & 94.1 & 98.6 & 80 & 94.7 & 3.7 \\
\hline Nonmasses & 6.7 & 93.3 & 75 & 82.4 & 90 & 85.2 & 7.4 \\
\hline Masses/Lumps & 0.9 & 99.1 & 68.1 & 90.8 & 95.9 & 91.6 & 7.3 \\
\hline All & 9.8 & 90.2 & 94.9 & 98.7 & 69.1 & 91.1 & 7.1 \\
\hline
\end{tabular}

US: ultrasound.

Table 5. Comparison between US-guided core-needle biopsy (CNB) and vacuum assisted biopsy (VAB) according to financial source (private versus healthcare insurance), with or without metal clip placement.

\begin{tabular}{|c|c|c|c|c|}
\hline Method of breast biopsy & Private & Insurance & Private + Metal Clip & Insurance + Metal Clip \\
\hline US-guided CNB & $x$ & Y & Z & W \\
\hline VAB & $2.2 x$ & $12.5 Y$ & $1.95 \mathrm{Z}$ & $5.2 \mathrm{~W}$ \\
\hline
\end{tabular}

US: ultrasound. 
and surgical biopsies when needed. Unfortunately, Brazilian public health system and some health insurers do not provide access to VAB because of its costs. Our study is the first Brazilian study to estimate costs of CNB and VAB considering the financial source where VAB is available. In our study, VAB costs 2.2 times US-guided CNB for private payment and 12.5 times when the payment is made by the healthcare insurer. However, placement of metal clip enhances CNB costs VAB still costs 1.95 times CNB (private) and 5.2 times (insurance).

Some limitations of this study are related to a retrospective study, such as missing data and the absence of a VAB arm for comparison to US-guided CNB and US-guided VAB arms. Herein, biopsies were performed by a team of radiologists with different years of experience in percutaneous biopsy. Also, a costeffective study was not performed, and the costs were estimated according to financial reports.

Nevertheless, this study was able to demonstrate that, for lesions bigger than $10 \mathrm{~mm}$, US-guided CNB with metal clip placement has high sensitivity, specificity, accuracy, and PPV and low FNR. So, our results suggest that US-guided CNB is an accurate approach to lesions that can be seen on US, besides being cost-effective.

\section{CONCLUSIONS}

US-guided CNB showed a low FNR, especially when done in lesions larger than $10 \mathrm{~mm}$. Also, US-guided CNB with metal clip placement has high sensitivity, specificity, accuracy, and PPV, even for lesions under $10 \mathrm{~mm}$. Moreover, US-guided CNB with metal clip placement is less expensive than VAB, regardless of the source of payment. In conclusion, US-guided CNB is an accurate approach to lesions that can be seen on US, besides being cost-effective.

\section{AUTHORS' CONTRIBUTIONS}

R.E.M., M.P.C., E.C.R.S.F., T.A.: data collection, investigation. M.S.: data analysis, writing - original draft, writing - review and editing. C.S.G., L.G., J.S.: performed core biopsies.

R.C.N. and S.S.S.: study design.

V.F.C.: statistical analysis.

A.G.V.B.: study design, performed core biopsies, data analysis, writing - review.

F.B.A.M.: project administration, study design, data analysis, writing - review.

\section{REFERENCES}

1. Lee BL, Liedke PER, Barrios CH, Simon SD, Finkelstein DM, Goss PE. Breast cancer in Brazil: Present status and future goals. Lancet Oncol. 2012;13(3):e95-102. http://dx.doi. org/10.1016/S1470-2045(11)70323-0

2. Makdissi FB, Leite FPM, Peres SV, Silva DRM e, Oliveira MM de, Lopez RVM, et al. Breast cancer survival in a brazilian cancer center: a cohort study of 5,095 patients. Mastology. 2019;29(1):3746. https://doi.org/10.29289/2594539420190000437

3. Bennett IC, Saboo A. The Evolving Role of Vacuum Assisted Biopsy of the Breast: A Progression from Fine-Needle Aspiration Biopsy. World J Surg. 2019;43:1054-61. https://doi. org/10.1007/s00268-018-04892-X

4. Nakano S, Imawari Y, Mibu A, Otsuka MH, Oinuma T. Differentiating vacuum-assisted breast biopsyfrom coreneedle biopsy: Is it necessary? Br J Radiol. 2018;91(1092):20180250. https://dx.doi.org/10.1259\%2Fbjr.20180250

5. Schulz-Wendtland R, Dankerl P, Bani MR, Fasching PA, Heusinger K, Lux MP, et al. Evaluation of a marker clip system in sonographically guided core needle biopsy for breast cancer localization before and after neoadjuvant chemotherapy. Geburtshilfe Frauenheilkd. 2017;77(2):169-75. https://dx.doi. org/10.1055\%2Fs-0042-124191

6. Andrade WP, Brites MR, Marques EF, Maciel M do S, Alves MGCP. Modelo alternativo para introdução de clipe cirúrgico para localização do leito tumoral em pacientes submetidos à quimioterapia neoadjuvante: descrição da técnica. Rev Bras Mastol. 2012;22(2):46-50.
7. Nigenda G, Gonzalez-Robledo MC, Gonzalez-Robledo LM, Bejarano-Arias RM. Breast cancer policy in Latin America: Account of achievements and challenges in five countries. Global Health. 2016;12:39. https://dx.doi.org/10.1186\%2Fs12992-016-0177-5

8. Alonso-Bartolomé P, Vega-Bolívar A, Torres-Tabanera M, Ortega E, Acebal-Blanco M, Garuo-Ayensa F, et al. Sonographically guided $11-\mathrm{G}$ directional vacuum-assisted breast biopsy as an alternative to surgical excision: Utility and cost study in probably benign lesions. Acta Radiol. 2004;45(4):390-6. https://doi.org/10.1080/02841850410005633

9. Londero V, Zuiani C, Linda A, Battigelli L, Brondani G, Bazzocchi M. Borderline breast lesions: Comparison of malignancy underestimation rates with 14-gauge core needle biopsy versus 11-gauge vacuum-assisted device. Eur Radiol. 2011;21(6):1200-6. https://doi.org/10.1007/s00330-010-2053-7

10. Zhou JY, Tang J, Wang ZL, Lv FQ, Luo YK, Qin HZ, et al. Accuracy of 16/18G core needle biopsy for ultrasound-visible breast lesions. World J Surg Oncol. 2014;12:7. https://dx.doi. org/10.1186\%2F1477-7819-12-7

11. Povoski SP, Jimenez RE, Wang WP. Ultrasound-guided diagnostic breast biopsy methodology: Retrospective comparison of the 8-gauge vacuum-assisted biopsy approach versus the spring-loaded 14-gauge core biopsy approach. World J Surg Oncol. 2011;9:87. https://doi.org/10.1186/1477-7819-9-87

12. O’Flynn EAM, Wilson ARM, Michell MJ. Image-guided breast biopsy: state-of-the-art. Clin Radiol. 2010;65(4):259-70. https:// doi.org/10.1016/j.crad.2010.01.008 
13. Ciatto S, Houssami N, Ambrogetti D, Bianchi S, Bonardi R, Brancato B, et al. Accuracy and underestimation of malignancy of breast core needle biopsy: The Florence experience of over 4000 consecutive biopsies. Breast Cancer Res Treat. 2007;101(3):291-7. https://doi.org/10.1007/s10549-006-9289-6

14. Ambrosio ACC, Kemp C, Gonçalves TD, Lima GR de. Valor da mamotomia no diagnóstico e na terapia de lesões não palpáveis. Rev Bras Ginecol Obs. 2004;26(1):37-42 https://doi. org/10.1590/S0100-72032004000100006
15. Deshaies I, Provencher L, Jacob S, Côté G, Robert J, Desbiens C, etal.Factors associated with upgrading to malignancy at surgery of atypical ductal hyperplasia diagnosed on core biopsy. Breast. 2011;20(1):50-5. https://doi.org/10.1016/j.breast.2010.06.004

16. Grady I, Vasquez T, Tawfik S, Grady S. Ultrasound-Guided Core-Needle Versus Vacuum-Assisted Breast Biopsy: A Cost Analysis Based on the American Society of Breast Surgeons' Mastery of Breast Surgery Registry. Ann Surg Oncol. 2017;24(3):676-82. https://doi.org/10.1245/s10434-016-5607-3 